\title{
Dr. Moser geht, und Dr. House darf bleiben
}

EMH-Newsservice

Seit der Vorankündigung in der Schweizerischen Ärztezeitung [1] ist ein grosser Teil der Ärzteschaft im «Doktor-Moser-Fieber». Viele Kolleginnen und Kollegen können die Ausstrahlung der ersten Folge der neuen Arztserie kaum erwarten; einige haben sich sogar spontan angeboten, als Schauspieler mitzuwirken. Zudem erhielt die FMH über Leserzuschriften wertvolle Anregungen, die schon jetzt zur Optimierung des Konzepts und des Drehbuchs der Serie massgeblich beigetragen haben - zum Beispiel, dem gesellschaftlichen Pluralismus stärker Ausdruck zu verleihen. So soll es schon bald eine Änderung bei der Besetzung der Hauptrolle geben, um den Frauenanteil unter Schweizer Chefärzten/-innen zu erhöhen. auch hier haben kreative Leservorschläge bereits Lösungen ermöglicht, die einer Beitragserhöhung effektiv entgegenwirken: Neben der Einnahme von Sponsorengeldern von einem unter anderem für seine Schokoladenprodukte bekannten Nahrungsmittelkonzern soll dadurch zusätzliches Geld in die Kasse der FMH fliessen, dass die Serienfolgen alle 15 Minuten durch Werbespots der Pharmaindustrie unterbrochen werden. Das Schweizerische Heilmittelinstitut hat die Werbebestimmungen für Arzneimittel eigens dafür gelockert. Jetzt muss nur noch das Schweizer Fernsehen überzeugt werden, die Sendezeit wegen der häufigen Unterbrechungen um eine Stunde bis $23.00 \mathrm{Uhr}$ zu verlängern.

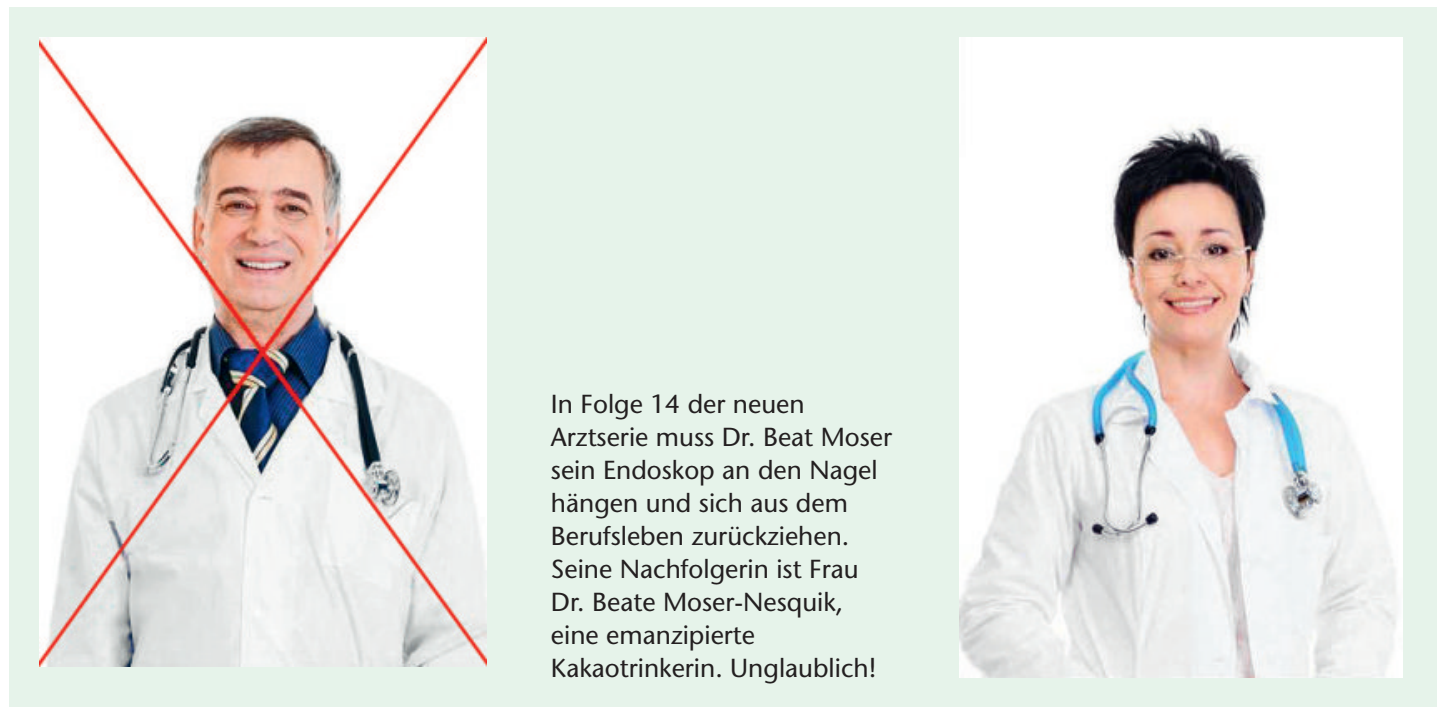

Ob es ihm gefällt oder nicht: Dr. Beat Moser muss in Folge 14 sein Endoskop an den Nagel hängen und sich ganz aus dem Berufsleben zurückziehen. Abgelöst wird er in Folge 15 von Dr. Beate Moser-Nesquik, einer emanzipierten Kakaotrinkerin. Am Titel der Sendung sind daher nur kleine Korrekturen notwendig («Dr. Beate Moser - die Ärztin, die die Schweiz von innen kennt»); dagegen fliegt der Beuteltee aus dem Programm. Die neue Chefärztin trägt einen Doppelnamen, vertritt einfache Prinzipien im Umgang mit ihren männlichen Kollegen und macht hier keine halben Sachen.

Die im Beitrag [1] angekündigte drastische Erhöhung der FMH-Mitgliedsbeiträge hat verhaltene Zustimmung bei der Ärzteschaft hervorgerufen. Aber
Alles könnte so schön sein, ... wenn es denn nur wahr wäre. Beide Doktores Moser hatten eine sehr kurze Sternstunde am Medizinerfirmament - nämlich nur am 1. April (April!). Freunde von Dr. House dürfen aufatmen, aber Fortbildungs-Credits gibt es für DVD-Staffeln von Grey's Anatomy nach wie vor keine!

Ihr EMH-Newsservice - immer am Puls der Zeit

1 EMH-Newsservice. Dr. House muss gehen, dafür kommt Dr. Moser. Schweiz Ärztezeitung. 2011;92(13):504-6. 